\title{
Justicia de élite: impunidad y desigualdad Elite justice: impunity and inequality
}

\author{
José de Jesús Pérez Martínez \\ El Colegio de San Luis, A.C: \\ josedejesusperezmartinez@gmail.com
}

Recibido / received: 11/12/2017

Aceptado / accepted: 27/02/2018

\section{DOI: https://doi.org/10.20318/eunomia.2018.4160}

\section{Resumen}

Se presenta un estudio interdisciplinario sobre los efectos sociales resultantes de la interacción entre impunidad y desigualdad socioeconómica en México centrado en el terreno sociológico. La relación recíproca entre ambas variables se observa en varios efectos sociales, como: la creciente vulnerabilidad de determinados sectores, al tiempo que el dominio político de ciertos sectores se vuelve económico y jurídico; una administración de justicia que hace distinción entre actores; o una variedad de derechos vulnerados, costos y carencias al enfrentar a la justicia, violaciones que escapan a la ley, o que se acumulan durante el proceso penal y permanecen sin castigo, con la consecuente ausencia de confianza en las autoridades judiciales

\section{Palabras clave}

Impunidad, desigualdad, justicia penal, corrupción, delito.

\begin{abstract}
An interdisciplinary study about the social effects after the interaction between impunity and socioeconomic inequality in Mexico is presented here located in the sociological field of studies. This reciprocal relation between these two variables can be seen in several social effects, such as: the exacerbation of the vulnerability of certain sectors, while the political domain of other sectors becomes economical and juridical; a justice administration that makes a distinction among the actors; or a variety of infringed rights, costs and lacks in the moment of facing the justice, violations that escape from the law, or either accumulate during the legal process and stay with no punishment, and the consequent lack of trust in the judicial authorities.
\end{abstract}

\section{Keywords}

Impunity, inequality, criminal justice, corruption, crime.

SUMARIO. 1. Introducción. 2. Reflexión teórica sobre el origen de ambos problemas sociales. 3. Reflejo cuantitativo de la experiencia mexicana. 3.1 La cadena de justicia y el papel de la autoridad. 3.2 Los vicios en la justicia criminal: impunidad y cifra negra. 3.3. Factores socioeconómicos que inciden en la justicia. 4. Conclusiones. 


\section{Introducción}

¿De qué manera se relacionan en la sociedad los efectos de la impunidad con los de la desigualdad socioeconómica? Para intentar responder a ello se han planteado las siguientes hipótesis: a) la desigualdad socioeconómica influye, aunque no necesariamente determina, en la impartición de justicia, generando diferentes grados de impunidad; b) la interacción entre impunidad y desigualdad socioeconómica genera repercusiones sociales que refuerzan o incrementan los mismos problemas; y c) la impunidad depende de otros factores además de la desigualdad socioeconómica, como son la corrupción, la violencia, las características del proceso judicial e incluso el tipo de agresión cometida, por lo que no podemos hablar de una relación causal explicativa unidireccional.

En busca de dar respuesta a lo anterior, el objetivo general de este estudio es explicar la repercusión social del cruce entre impunidad y desigualdad socioeconómica, mientras los efectos sociales observados en el contexto permitan reconocer una relación dinámica entre ambos problemas.

La impunidad implica que la justicia ha fallado en sus principios, que se ha dejado a los criminales sin un castigo, y manda a la sociedad un mensaje de que el castigo penal es solo una remota posibilidad. En un escenario que promueve conductas ilícitas con un Estado incapaz de proteger a sus ciudadanos contra el crimen, la impunidad es un problema que, cuando se ha estudiado, ha sido desde las perspectivas jurídicas. No es un problema aislado, se rodea de obstáculos sociales como la corrupción o la violencia, pero, en este caso, destaca la importancia de la brecha de desigualdad socioeconómica entre la élite política y el resto de la población, un problema estudiado tradicionalmente por el enfoque económico.

El presente estudio resume los hallazgos de la interacción de áreas disciplinares como el Derecho, la Economía, la Ciencia Política y la Sociología, pero tratados específicamente desde la Sociología Política. La desigualdad ha sido definida y considerada de diversas maneras, y está claro que no toda capacidad es medible en dinero, pero, para no estancarse en un debate filosófico en esta etapa, se considera que los términos de desigualdad socioeconómica importantes para este estudio son precisamente los referentes al nivel de ingreso, pues los servicios de defensa ante los tribunales de justicia pueden llevar previa una mediación de pago de servicios cuando se opta por una defensa privada, por lo menos en México. Esta desigualdad en el ingreso termina por convertirse en una desigualdad en el acceso a la justicia y en la defensa ante las cortes penales.

La impunidad denota la ausencia de un castigo para el agresor, aunque se percibe en diferentes grados en el sistema penal dependiendo el tipo de agresión. Las agresiones no son únicamente los delitos tipificados, además existen otras violaciones de Derechos Humanos derivadas de decisiones arbitrarias de autoridades, o perpetuadas por instancias estatales o actores privados, que ni siquiera son contempladas en los códigos penales, por lo que se pueden pensar como casos de impunidad de iure, escapando desde el instante del supuesto a los alcances de la ley. 
2. Reflexión teórica sobre el origen de ambos problemas sociales

Aunque son problemas que se estudian tradicionalmente por distintas áreas disciplinares, si nos remontamos a la discusión filosófica, se pueden vincular dos campos alejados sobre el terreno de lo social. En sintonía con el planteamiento de no buscar una correlación directa ni unilateral, se buscan los rastros de una relación con dinamismo y reciprocidad en las percepciones de la sociedad. Los problemas de desigualdad e impunidad tienen cierto contacto social, pero la división disciplinar no lo ha dejado ver del todo claro, es más útil el enfoque multidisciplinar para poder observarlo.

El crecimiento en la desigualdad se ha dado desde las bases del sistema económico neoliberal, pues las posibilidades de libre acumulación implican la formación de elites poderosas, con capacidad de manipular o imponerse en los ámbitos político, social y económico. Poco a poco, lo social se ha sometido al mercado, todos los aspectos de la vida se han vuelto mercancía acumulable y transferible. El fetiche es el dinero y su valor, que se proyecta sobre el valor del trabajo y la persona que lo hace (Marx, 1867: 101)

Junto al capitalismo vino la abstracción, el cálculo, la especulación por encima de la necesidad humana. La máquina (o sistema capitalista) dicta los valores a tomar en cuenta y lo que debe entenderse por Justicia (Mumford, 1997: 13-17, 44 ), de igual manera, impone nuevos hábitos y va moldeando la moral y los ideales de la sociedad, dejando a su paso un acceso desigual a los satisfactores. Cuando lo acumulado rinde más ganancias que el trabajo o que el capital, se está promoviendo una desigualdad en la que se impone quien antes acumuló, transmitiendo desigualdades entre generaciones por medio de las herencias (Piketty, 2014). Es muy probable que la descendencia de quien se impuso en la acumulación tenga un punto de partida ventajoso sobre el resto de los ciudadanos en términos económicos, sociales y políticos, pues, en todo tipo de instituciones, se reproducen los preceptos de lo económico, que se impone sobre la justicia y lo social, apoderándose de las estructuras (Polanyi, 1944).

Con lo anterior, no es necesario seguir fingiendo que hay una mano invisible. Es notorio, en términos sociales, a quién beneficia esa mano y por quién puede ser movida (Bauman, 2014: 51-52). Las élites políticas y económicas reciben las ventajas que se amplían a todo ámbito de la vida social. Siempre que la acumulación sea ilimitada terminará por generar abundancia, pero se genera a la par su equivalente en miseria, va creciendo la brecha. Los ciudadanos de una misma sociedad habitan un mismo territorio, pero viven diferentes mundos, dejando un panorama al que Sousa Santos (2009: 563) identifica como fascismo social.

En este sistema económico, del nivel de ingreso depende gran parte de la realización de capacidades humanas (o tener siquiera la opción de realizarlas, aunque por ciertas decisiones no se logre). La riqueza consiste precisamente en poder elegir entre varias opciones. La libertad de una persona consiste entonces en poder fijar sus fines y el poder conseguirlos (Sen, 1992: 45-52). La pobreza, por el contrario, restringe el rango de elecciones, el pobre debe ponderar qué necesidad satisface, y en particular, los costos para hacer frente a la justicia, que no suelen estar en el presupuesto básico de una familia cuyos recursos se destinan a la subsistencia básica. La carencia acarrea un estigma social (Goffman, 2012: 23) del que se cuelgan las desventajas sociales, no todas visibles. En contraparte, la élite obtiene además de la abundancia, cuestiones como prestigio y fama. La obsesión por poder siempre elegir, coloca en un estatus alto al que puede hacerlo, le da mérito social (Bauman, 2014: 39). Hoy en día, junto con la acumulación viene la 
ostentación, el mercado ha dictado el valor de mostrar el poder al resto de la sociedad (Raphael, 2014).

Las elites conformadas obtienen, junto con el prestigio social, el valor del capital, los medios de producción o acumulación y las posibilidades de manipulación institucional. Socialmente, la élite es un lugar reducido, menos del $1 \%$ es el que es capaz de manipular la estructura institucional (Piketty, 2014). Uno de sus mecanismos es ir ocupando poco a poco los puestos públicos. Cuando el desempeño es pobre o tendencioso, las élites socavan la confianza en las instituciones. Son insensibles a la realidad popular y viven otro mundo. La influencia política es un componente necesario para la desigualdad, pues cambia las decisiones, manipula las instituciones e inclina la balanza en favor de quien goza de esa influencia, dejando de lado a la justicia social. Es entonces el puesto público visto como una unidad de ganancias, por lo que informalmente se paga. El funcionario que llega mediante la influencia, o que solo se sirve del puesto público, es asimilado socialmente como un parasito, algo que ocurre con todo tipo de puestos, incluso aquellos del Poder Judicial.

El aparato judicial y demás instituciones que funcionan en sintonía con el modelo capitalista sirven para proteger los privilegios, están al servicio de los postulados económicos de progreso y crecimiento (Illich, 2011: 463). El Derecho penal no es hecho por y para todos, la mayoría de la población no participa en ello, lo cual, en el fondo, promueve asimetrías (Foucault, 1975: 320-321). Lo mismo pasa con el mantenimiento del orden, una atribución que no se encomienda a todos, dejando espacios para actuaciones excesivas y arbitrarias de aquellos encargados de ejercer el control (Gellner, 1991: 118-122).

Así pues, con el tiempo, la justicia se ha adaptado al sistema económico y ha protegido los valores que le acompañan. El esquema de castigo moderno ha hecho lo propio al respecto, pues, aún con penas alternativas, el castigo sigue recayendo en la economía política del cuerpo (Foucault, 1975: 34). La prisión se ha aparejado al sistema capitalista en la época contemporánea como el esquema dominante de castigo para los crímenes. Su aplicación retira libertades y derechos, deja al preso fuera del mercado laboral y le coarta la mayoría de sus capacidades. Pero no solo a él, también deja también muchos estragos para su familia. La prisión no retribuye en realidad beneficios tangibles a la sociedad, el daño no es reparado, pero sí le genera costos a la sociedad y crea criminales en un entorno que contamina a quien ingresa. La prisión ha fracasado al querer reducir la criminalidad, es común que al interior haya decisiones arbitrarias, corrupción, abuso de poder. Es un obstáculo a la movilidad social más que un beneficio social.

Existen hoy en día sociedades como la mexicana, en las que cualquier tipo de delito busca castigarse con cárcel, y otras en las que una variedad de castigos que se aplican en la práctica cotidiana aligeran la carga de las prisiones. Siendo cualquiera que sea el caso, podemos entender a la impunidad en el ámbito de la justicia penal, como la agresión cometida que permanece sin castigo alguno. La impunidad tiene múltiples dimensiones y causas, y va a la par de grandes problemas como la violencia, la corrupción y la inseguridad. Es un fenómeno de difícil medición por cuestiones como la falta de denuncia, las lagunas legales o los datos maquillados que brinda el gobierno a las instancias evaluadoras o estadísticas. Por ello, son importantes los datos de las organizaciones civiles especializadas para poder ampliar el seguimiento.

Es necesario un concepto más amplio de impunidad, pues solo enfocarse en el delito puede dejar fuera muchas agresiones. Hay actos arbitrarios de la autoridad 
que permanecen sin castigo o que no se consideran como delitos. La impunidad va más allá de la ausencia de castigo, es un fenómeno que tolera y que promueve el crimen sin consecuencias para el que agrede a la sociedad. Se han unido hoy los ideales de lo económico y de la Justicia. El sistema económico no solo distribuye la riqueza y la desigualdad, también se ha encargado de repartir el acceso a justicia y a las ilegalidades. Estas bases teóricas que ayudan a revisar la relación dinámica entre impunidad y desigualdad se vuelven más tangibles al acercarse al plano práctico de la realidad social.

\section{Reflejo cuantitativo de la experiencia mexicana}

En el trayecto del estudio que da pie al presente escrito, se ha realizado un seguimiento de los datos relativos al sistema de justicia, el sistema penitenciario y a mediciones de desigualdad socioeconómica de fuentes oficiales de Gobierno, publicados en su mayor parte por el Instituto Nacional de Estadística y Geografía (INEGI). Esta información ha sido contrastada y complementada con los datos generados por instituciones académicas y organizaciones de la sociedad civil que se han especializado en este tipo de asuntos. Gracias a ello, se han realizado diversos hallazgos que permiten identificar una problemática compleja a partir de la interacción entre la desigualdad socioeconómica y la impunidad de una manera más tangible.

El seguimiento de datos para el estudio abarca hasta fines de 2015, un año antes del límite para completar la implementación nacional del nuevo sistema penal acusatorio, derivado de la reforma judicial de 2008. México es un excelente ejemplo de una sociedad en donde conviven la impunidad y la desigualdad socioeconómica en niveles extremadamente altos. Son problemas tan extendidos en México que incluso han llegado a ser vistos como parte de la normalidad social, como algo que se piensa colectivamente como obvio en el funcionamiento del propio sistema y con lo que se lidia por costumbre. Los datos obtenidos respecto a lo expuesto anteriormente y los hallazgos que de ello se desprenden se sintetizan en adelante para ilustrar la medición que se propone de la impunidad en referencia a la desigualdad socioeconómica.

\subsection{La cadena de justicia y el papel de la autoridad}

El sistema de justicia penal mexicano atraviesa una etapa de cambio que se genera a partir de la reforma constitucional de 2008, que planeaba al 2016 como límite de tiempo para consolidar el paso hacia el esquema acusatorio de justicia penal. El sistema acusatorio ha entrado en vigor a destiempo a lo largo del territorio nacional, por lo que los datos para juzgar su desempeño son hasta ahora insuficientes. Es por ello que los datos utilizados para este estudio se ubican en el anterior sistema penal, llamado también inquisitivo, un esquema que ha echado raíces en la mentalidad de las autoridades judiciales.

Los procedimientos propios de este sistema previo son en su mayoría de naturaleza escrita, implican un análisis posterior y derivan en una decisión más secreta; al ser escritos, le dan especial importancia a los formalismos y culminan en una colección de trámites burocráticos con la pérdida de tiempo que esto implica, provocando procesos lentos y tediosos. Las pruebas se unen a ese ritualismo de lo formal con una validez que se les predetermina en la ley, descuidando el fondo. 
Incluso una confesión firmada puede ser prueba única y suficiente para condenar a alguien, aún si se obtuvo en una posible situación de abuso, tortura o extorsión. Las partes en realidad no tienen un dialogo, o quizás se desconozcan entre ellas y el resultado que se busca de este proceso judicial es la pena para el acusado, destacando la importancia del castigo, pero olvidándose de resarcir o reparar el daño causado para la sociedad o la víctima, de prevenir delitos o de reinsertar al delincuente a la sociedad, incrementando el descontento social.

Para poder imponer un castigo en este esquema, se debe proceder mediante el debido juicio penal desarrollado ante el tribunal o autoridad correspondiente. A esto le corresponden una serie de pasos en el procedimiento que pueden identificarse como la cadena de justicia (Gráfica 1), la cual ha sido ilustrada para fines de este estudio con una gráfica de Red Social, elaborada mediante el software Cytoscape, en donde los nodos no se corresponden con los actores como tradicionalmente se hace, sino que los nodos que se identifican aquí son las etapas de dicha cadena de justicia.

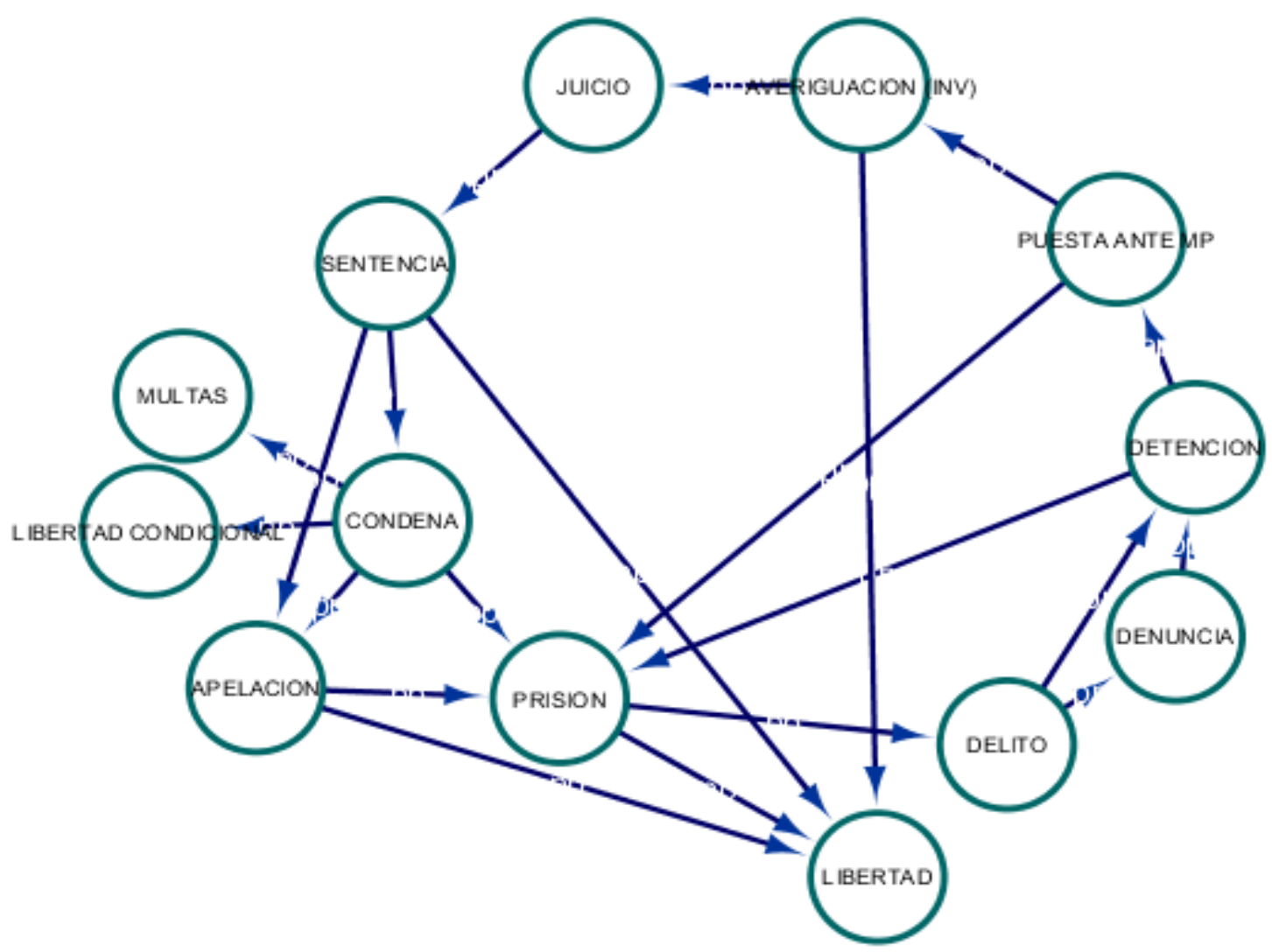

Gráfica 1 - Red de etapas en la Cadena de Justicia Fuente: elaboración propia en Cytoscape

Partiendo del momento del delito, se puede pasar directamente a la detención en los casos de flagrancia, o bien cumplir con el requisito de la denuncia que desencadena la investigación. Al ser detenido el agresor, lo normal es que sea puesto a disposición del Ministerio Público y, después, se integra el expediente con 
la averiguación previa y es turnado a juicio, donde el juez analizará el caso para poder dictar sentencia (que puede consistir en una condena o la libertad, o que puede ser apelada en otra instancia). Finalmente, si la condena lo prescribe, el agresor purga su pena alternativa o su pena en prisión: quien al haber pagado su condena recupera su anterior estado de libertad. Se puede observar en esta gráfica que cabe la posibilidad de llegar a la cárcel sin haber pasado por el juicio, pues la prisión preventiva es una de las situaciones de las que se abusa en México, lo cual constituye una violación de los derechos de las personas que deja en prisión que no han sido juzgadas apropiadamente como culpables.

Como un aporte metodológico, se modificó esa misma gráfica para agregar su relación con los actores en cada etapa del proceso dando como resultado la Gráfica 2, en la que se incorporan a los actores o roles principales que interactúan en el proceso penal, en forma triangular. Se destacan en el centro los triángulos invertidos referentes al victimario y su defensor, pues servirán para una posterior comparación en el nivel de los hallazgos. Partiendo nuevamente desde la etapa del delito, vemos cómo entran en acción autoridades o roles como la víctima, su abogado y su familia, la Policía, el agente del Ministerio Público, el Juez Penal y el Juez de Amparo o de segunda instancia, todos ellos con sus respectivos secretarios. Finalmente aparecen los custodios de la prisión y el resto de los criminales que la habitan.

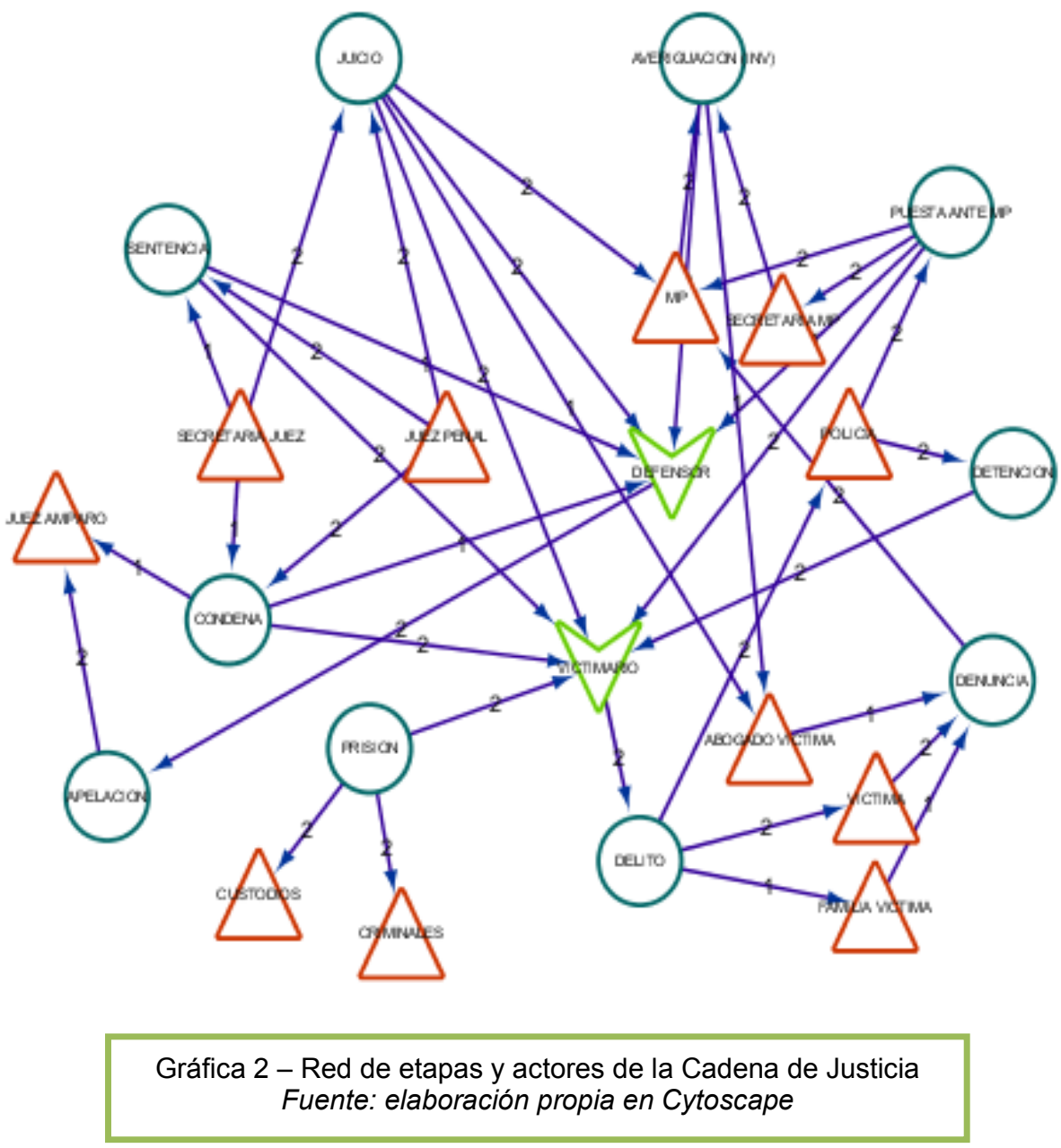


Según los datos del Índice Global de Impunidad (UDLAP, 2015: 53-58), para la fecha de su elaboración, México contaba con 4,28 jueces por cada 100.000 habitantes, mientras que, en los 59 países comparados en el Índice, el promedio fue de 17 jueces. En países como Croacia, Eslovenia y República Checa, el promedio de jueces por cada 100.000 habitantes es de 45. Estos países, a su vez, ocupaban los mejores puestos en cuanto a menor Índice de Impunidad. Otro dato relevante es el porcentaje de aquellos que son detenidos sin proceso ni sentencia, pues en México es el $46,86 \%$ de los detenidos quienes están en esta situación, mientras que en Croacia es la mitad, el $23 \%$.

Un hallazgo importante en términos de justicia es que la Policía como conjunto ha demostrado ser el eslabón más débil de la cadena de justicia mexicana, pues su promedio de 485 elementos por cada 100 mil habitantes se ubica por encima del promedio internacional de 342. Sin embargo, el problema con la Policía no es un número insuficiente, sino el pobre desempeño y la mala percepción que les tiene la ciudadanía. Muchos de los elementos policiacos aún no han sido evaluados; y de los que han sido evaluados más de 28 mil no han pasado el control de confianza, esto es cerca del $9 \%$ del cuerpo policiaco que continúan en funciones a pesar de reprobar la evaluación, sin que eso implicara su separación del cargo.

Parte de las deficiencias policiacas se engloban en el mal trato que dan a los ciudadanos, llegando a considerarse este abusivo y excesivo. Las vulneraciones a los Derechos Humanos se presentan para ambas partes: la víctima del delito recibe los daños propios de la agresión o el delito cometidos, contra varios derechos básicos como la vida, la libertad o la integridad. Pero también es posible identificar que la autoridad le falla al resguardar su derecho a la protección y a la seguridad, además de no generar los medios adecuados y eficientes para denunciar y acceder a los procesos de justicia.

La situación es más difícil desde el punto de vista del acusado, llegando a vivir situaciones como la tortura generalizada, las desapariciones forzadas, el encarcelamiento político y hasta las ejecuciones extrajudiciales, que reflejan el lado más oscuro del abuso de poder, que no son lo más común, pero suelen presentarse a lo largo del proceso penal. En la Encuesta a Población en Reclusión 2012, los internos contestaron que las violaciones más comunes que sufrieron en la etapa de la detención fueron no recibir orden de aprehensión por escrito, no ser tratados con respeto, no recibir una identificación de quien les detuvo ni recibir información de a qué corporación policiaca pertenecían, no le escucharse lo que tenía que decir, ser amenazados, quitársele pertenencias, golpeársele, ser insultado o humillado, todo esto en más de la mitad de los casos. En la etapa de la puesta ante el Ministerio Público no cesan las vulneraciones, las más reiteradas fueron el hecho de no informarles de su derecho a no declarar; no brindarles las posibilidades de hacer una llamada telefónica; no informar del derecho a tener un abogado o una defensa justa; y no explicar los motivos de su estancia en ese lugar. Durante el juicio, solamente el $24 \%$ contó con un defensor privado. Solamente el $48,5 \%$ confesó ser culpable porque efectivamente lo era, el resto declaró ser culpable luego de ser torturado, amenazado, presionado, engañado en su persona o su familia.

Los abusos no se detienen al llegar a prisión sin importar si ha llegado ahí por ser culpable. Los internos suelen toparse con más violaciones como ver condicionados sus derechos y bienes más básicos mediante cuotas (económicas 0 de servicios), además de habitar un entorno que atenta constantemente contra la dignidad humana física y psicológica, con condiciones como el aislamiento, la falta de separación entre internos, el hacinamiento derivado de la sobrepoblación, la incomunicación y la falta de salubridad que contribuyen a degradar la salud e 
integridad física y mental. Hay fallas en la atención médica, la alimentación, el medio ambiente saludable, el desarrollo psico-sexual, el trato digno, la comunicación familiar, el sano esparcimiento, y la protección contra la violencia y el uso de la fuerza.

El aparato estatal que cuida la observancia de la legislación y vela por garantizar seguridad y respeto a los ciudadanos es la última esperanza de protección contra las agresiones que pueden ocurrir en el tejido social. El funcionamiento de este organismo determinará si el pueblo puede sentirse protegido por sus autoridades, y si en realidad lo está. La serie de violaciones y abusos que se han mencionado anteriormente, además de la falta de resultados observada por la población, han dejado a la Policía en el segundo lugar de las instituciones con menos confianza ciudadana (Consulta Mitofsky, 2012), solamente por encima de los Diputados, y por debajo de los Partidos Políticos y los Senadores. En la Encuesta Nacional de Victimización y Percepción Sobre Seguridad Pública (ENVIPE) de INEGI (2013a), más de la mitad de la población considera como altamente corruptas a la Policía de Tránsito, la Policía Municipal, los Jueces, el Ministerio Público, la Policía Estatal, la Policía Judicial, la Procuraduría General de la República y la Policía Federal.

Una de las consecuencias de esa mala percepción de confianza en las instituciones de justicia por parte de la población, es que la ciudadanía no acostumbra a denunciar los delitos sufridos. De acuerdo con las encuestas de victimización (INEGI, 2013b), las principales causas para no haber denunciado un delito son: considerar que no sirve para nada, la falta de confianza en la autoridad, malas experiencias en el pasado, miedo a represalias del delincuente, que toma mucho tiempo, o no saber con quién acudir; la mayoría de ellas, causas atribuibles a la autoridad. Se necesita un entorno con mecanismos más efectivos y menos formalismos o requisitos para denunciar, pues diferentes tipos de delitos debieran admitir diferentes tipos de denuncia.

\subsection{Los vicios en la justicia criminal: Impunidad y Cifra Negra}

La impunidad es algo difícil de medir por naturaleza, pues se refiere a las ausencias de castigo, ausencias que escapan a mediciones directas. Sin embargo, es posible observar distintos comportamientos del aparato judicial, resultando en distintos grados de impunidad, al igual que distintos grados de cifra negra en función al delito, ya que cada tipo delictivo tiene sus características constitutivas, entre ellas las económicas y sociales.

Impunidad judicial para fines del presente análisis se interpreta como la ausencia de un castigo tras la actuación judicial para un delito tipificado que ha sido denunciado. Cifra negra es el gran número de delitos que se cometen, pero que, por cualquier razón, no han sido denunciados, siendo prácticamente imposible iniciar un procedimiento penal. Si se unen ambas formas de ausencia de castigo, es posible proponer la medición de la impunidad general, que abarcaría al conjunto de delitos que, ya sea por falta de denuncia (cifra negra), o por una mala actuación judicial (impunidad judicial), permanecen sin castigo alguno. Todo lo anterior hace referencia a una impunidad de facto, pues ocurre en la práctica.

Es importante distinguir lo anterior de la impunidad de iure, que incluye todos los casos en los que, de entrada, la ley no tipifica como delito la agresión o violación de ciertos Derechos Fundamentales, quedando automáticamente fuera del rango de 
competencia de la autoridad judicial; o agresiones que son juzgadas por tribunales especiales, como los militares o eclesiásticos; agresiones cometidas por los Estados o sus autoridades que no son incluidos en la legislación; cuando el castigo y la investigación se encomiendan a autoridades externas como comisiones legislativas o auditorias que carecen de fuerza punitiva; los diversos tipos de fueros o inmunidad; cuando la víctima desconoce que la agresión que sufre constituye un delito o no hay medios para castigarla; o bien, cuando no es posible identificar a una persona física como el culpable directo.

En las disciplinas jurídicas una dicotomía común es lo que se da de facto y de iure, lo que se relaciona con distinguir si nos referimos a algo de hecho o de derecho, similar a la distinción entre la teoría y la práctica. Mientras de facto es un ámbito observable en las acciones, el ámbito de iure se reserva para lo observable en la ley y demás fuentes del derecho, ya sea de una manera literal o hermenéutica. Una de las propuestas de esta investigación es reconocer que la impunidad puede presentarse de ambas formas. La impunidad de hecho o de facto es la que reconocemos al existir una ausencia de castigo para una agresión contemplada como delito con sanción prevista, pero que de hecho no es aplicada; mientras que, la impunidad de derecho o de iure es aquella en que la agresión ni siquiera es tomada en cuenta por la Ley como algo susceptible de ser castigado, o bien, la propia Ley marca una excepción para imponer el castigo. La impunidad de iure escapa más a la vista que la impunidad de facto, por lo que no ha habido hasta ahora una medición completa, y esto es apenas una propuesta para no perderla de vista, además de que, pensar en medirla puede ser un trabajo más complejo que involucra cuestiones hermenéuticas profundas, culturales, políticas, legislativas, psicológicas y de percepción subjetiva difíciles de enlazar de manera cuantitativa. Por ello la impunidad de iure no constituye el foco central de este estudio.

Regresando a la impunidad de facto (en adelante simplemente impunidad) y a la cifra negra, lo complicado es medir las ausencias (de castigo o de denuncia respectivamente) y la facilidad para caer en errores de cálculo o para menospreciar la magnitud del problema. Siendo estas las que han llevado a la propuesta de medición realizada. Haciendo uso de las bases de datos de la Agencia Oficial de Estadísticas de México, el INEGI, que dispone muestreos anuales confiables en cuanto a percepción ciudadana y que para mediciones gubernamentales usa datos brindados por las propias instancias. Los datos de INEGI han sido procesados a través de SPSS y la finalidad de los cálculos generados es apreciar las variaciones en el funcionamiento de los procesos judiciales, así como analizar la información sobre la comisión, denuncia y procesamiento de diferentes tipos de delitos para verificar que la impartición de justicia tiene diferente efectividad tratándose de distintos tipos delictivos, resultando en diferentes grados de impunidad y cifra negra.

Debido a la compatibilidad de fuentes y a la presencia de un indicador en particular (referente a la denuncia y procesamiento según tipo delictivo) se utilizaron dos encuestas del INEGI, ambas de 2013, que, a su vez, reflejan los datos de 2012. La primera es la Encuesta Nacional de Victimización y Percepción Sobre Seguridad Pública (ENVIPE), con la que es posible hacer cálculos como: el costo promedio del delito, el estancamiento de la averiguación o incluso la cifra negra, ya que esta encuesta, como su nombre lo específica, toma en cuenta la percepción de la víctima, sin importar aún la reacción judicial. El problema al ser enfocada a la percepción ciudadana es que solo incorpora 9 tipos delictivos específicos y otras dos categorías, dejando fuera algunos delitos de difícil percepción directa como el narcomenudeo o la evasión de presos, así como delitos con dificultades para su comunicación en este tipo de instrumentos como el homicidio o la privación de libertad. 
La segunda fuente fue el Censo Nacional de Impartición de Justicia Estatal (CNIJE) que tiene limitaciones para calcular la cifra negra y la impunidad general, pero funciona de manera más exacta para la impunidad judicial, permitiendo monitorear la calidad del proceso y de la condena una vez que un delito ha sido denunciado y el proceso ha sido abierto. Además, este censo ha permitido observar la victimización $\mathrm{y}$, específicamente, la impunidad judicial para un catálogo más amplio de 32 tipos delictivos y otras 11 categorías. En los casos de los delitos del CNIJE, en los que no hay datos de percepción que permiten calcular la cifra negra, ha sido usado el promedio general de cifra negra publicado por INEGI $(92,8 \%)$ como promedio para el año 2012 (reportado en las encuestas de 2013).

Para el Tratamiento en SPSS, la categoría de observación fue el tipo delictivo. Se generaron porcentajes como variables transformadas y también se asignaron valores ordinales para hacer gráficas y cálculos cruzados. El valor 0 fue asignado como perdido, 1 para situación ideal y cuanto más alto era el valor, más preocupante sería la situación (3, 4 o 5 dependiendo el caso). De acuerdo con las funciones de análisis de resultados respecto a la cifra negra e impunidad fue posible encontrar los siguientes hallazgos:

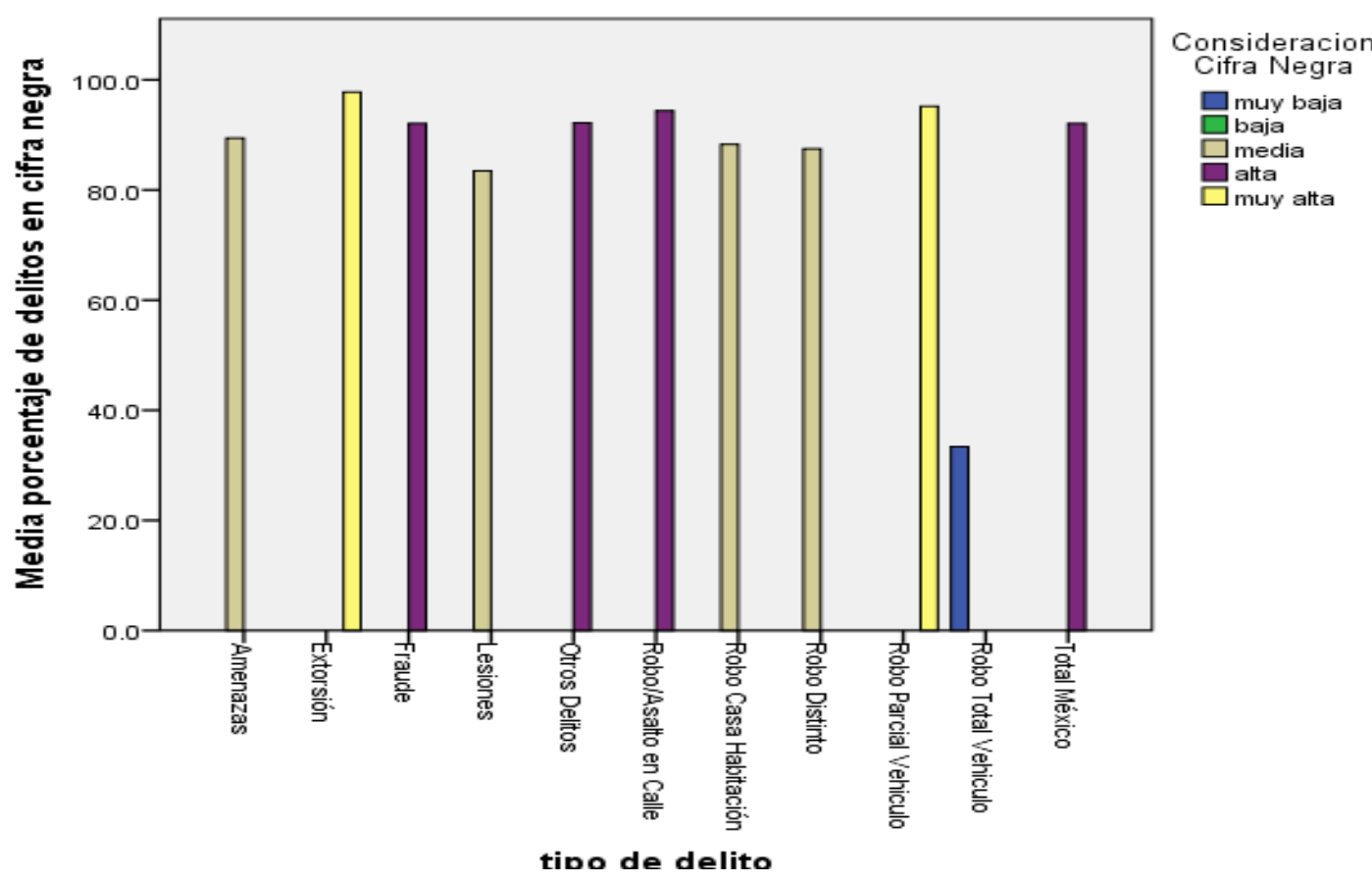

En la Gráfica 3 - Gráfica de barras, cifra negra 2013 posible observar el cifra negra (Gráfica INEGI

ENVIPE es alto nivel de 3), cerca de 9 de cada 10 tipos delictivos tienen cifra negra superior a $85 \%$ (cuya categoría fue media), solo un tipo delictivo tiene una cifra negra menor al $80 \%$. Esto quiere decir que, en esos tipos delictivos, solamente 2 de cada 10 incidentes se denuncian y logran abrir el proceso penal. En contraparte, solo un tipo delictivo registra un nivel medio de denuncia, el robo de auto. Para esto, una de las posibilidades es que las personas denuncian el delito por ser uno de los requisitos de las aseguradoras para reclamar la póliza de indemnización. 
Pasando a la impunidad judicial, el análisis se ha dividido en tres etapas: al inicio de proceso (cuando se integra la averiguación previa); al término del proceso (cuando termina el juicio); y en la sentencia condenatoria (que hace pasar a la aplicación de la pena). Este comparativo de impunidad en las distintas etapas se realizó con los datos de CNIJE y se muestran los hallazgos en la Gráfica 4 . Se puede observar que, mientras más avanza el proceso, mayor nivel de impunidad judicial se presenta, se van cerrando expedientes sin que se deba precisamente a que hayan sido concluidos. El contraste más notorio se halla entre la etapa inicial, en que predomina la baja impunidad, y la etapa final, con impunidad predominantemente media, lo que genera muchas dudas sobre la funcionalidad del sistema judicial y los factores externos que llegan a influir en el trayecto. En la etapa de sentencia condenatoria la impunidad alta es lo que predomina en la mayoría de los delitos, solo 9 de 43 categorías siguen en el rango medio (secuestro exprés y los diversos tipos de robo); mientras que solamente dos tipos delictivos (robo en transporte público colectivo y el tipo no especificado) presentan baja impunidad hasta la sentencia condenatoria.
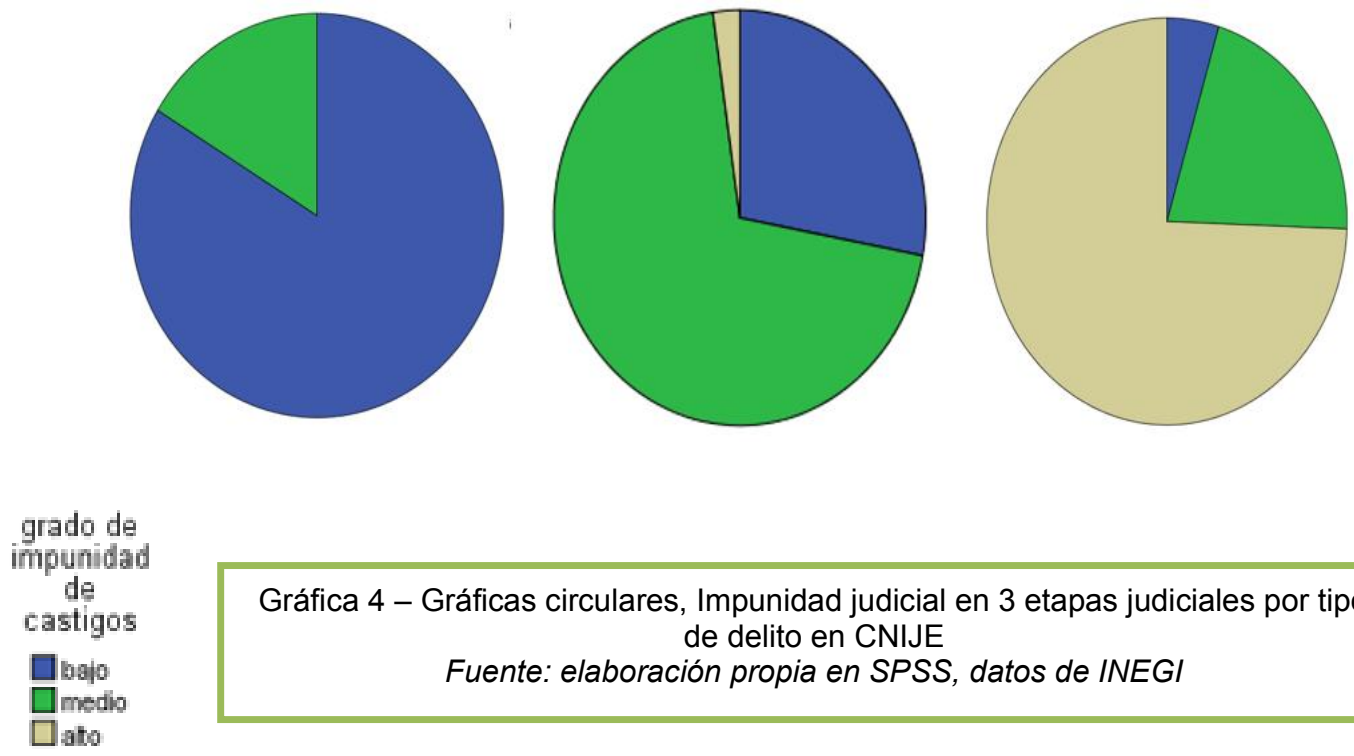

$$
\begin{array}{r}
\text { Gráfica } 4 \text { - Gráficas circulares, Impunidad judicial en } 3 \text { etapas judiciales por tipo } \\
\text { de delito en CNIJE } \\
\text { Fuente: elaboración propia en SPSS, datos de INEGI }
\end{array}
$$

La impunidad general incorpora todo lo calculado anteriormente, la impunidad judicial en todas sus etapas y la cifra negra. El resultado del cálculo de la impunidad general para todos los tipos delictivos en México fue mayor en todos los casos al $90 \%$, llegando en algunos casos a porcentajes cercanos al $99 \%$.

\subsection{Factores socioeconómicos que inciden en la justicia}

¿Qué sucede cuando se incorpora el factor de la desigualdad socioeconómica en la ecuación de la Justicia? Las instituciones quedan en peligro de desviar sus funciones originales, pueden ser usadas para reproducir la desigualdad y reforzar el poder de aquellos en el cargo, o de sus allegados, permitiendo así a las elites adueñarse de cierta institución, además de los privilegios y facultades propios de ella.

Existe una multitud de casos que van desde los acusados que, a pesar de su inocencia, terminan en prisión por falta de medios para defenderse; los típicos funcionarios que violan la ley y se escudan en la figura de la inmunidad; al igual que 
personas con cierta fama o poder económico que logran convencer a la opinión pública o a los jueces de su pseudo-inocencia; hasta casos en los que es más que evidente la responsabilidad del acusado y en los que inexplicablemente el caso se cierra o se le otorga la libertad quedando ocultas las razones de esa puesta en libertad en la oscuridad de los expedientes.

La Justicia tiene un papel fundamental para el desarrollo humano, de manera directa e indirecta, y la falta de ella, puede significar para alguien una desventaja tremenda en términos sociales, al igual que para la comunidad entera. Las instituciones encargadas de proteger los Derechos Humanos a nivel nacional deben ostentar la solidez y la autonomía necesarias para garantizar esa protección a los individuos, ya que de nada sirve el gran avance en este terreno a nivel internacional, si en el nivel nacional estas instancias no cuentan con los recursos para hacerlos valer.

La Justicia, el acceso a ella o su impartición no son aspectos de fácil medición, inciden muchos factores subjetivos y a veces contrapuestos. Lo que para alguno puede parecer justo en cierta medida, para otro puede significar la injusticia total. Sin embargo, la carencia de justicia en aspectos criminales puede ocasionar la pérdida de las oportunidades para una vida digna, larga o saludable, al igual que puede representar un bloqueo a necesidades tan básicas como el acceso al conocimiento, al empleo o a los ingresos.

Todo crimen o agresión, lleva implícito un coste para aquel que lo sufre, en muchas ocasiones cuantificable en dinero, aunque en otras ocasiones con pérdidas de otra índole. El coste no es solo para quien sufre la agresión, pues generalmente se ven afectados los miembros de su familia, como víctimas indirectas y posteriores. Además de los familiares, la agresión tiene repercusiones económicas inclusive en entidades jurídicas como las empresas y las organizaciones, al igual que los costes para la sociedad en su conjunto. No todos los costes que le ocasiona el crimen a la sociedad son de carácter económico, existen otras grandes pérdidas para la comunidad: pérdidas en la calidad de la democracia, en la confianza y los vínculos sociales, en los espacios de cooperación; aumenta la vulnerabilidad de grupos como mujeres y jóvenes; la inseguridad genera un temor y preocupación notorios en la población, que afecta su desarrollo social y laboral; el comercio se ve afectado por las restricciones; aumenta el número de pobladores en niveles de pobreza, un hogar de ingreso medio al ser afectado por un delito podría ingresar rápidamente en las filas de la pobreza.

Uno de los costes indirectos del delito que se deben considerar de manera importante, y no por el monto que representa, sino por sus repercusiones sociales, es el rubro penitenciario. Según el reporte de México Evalúa (2013) lo que se invierte de los impuestos en mantener a un recluso equivale a $\$ 4.200 \mathrm{MXN}$ mensuales, un monto muy superior a lo que reciben los beneficiarios de ciertos programas de gobierno mediante becas educativas, o transferencias por su edad avanzada o grado de marginación, o lo que gana un obrero con un salario mínimo. Si la pena sobrepasa un año, este costo implica $\$ 50.400 \mathrm{MXN}$ anuales, algo que nos pone a pensar si en realidad es conveniente o costeable mantener a alguien interno por un crimen cometido por cuantías equivalentes o menores a $\$ 5.000 \mathrm{MXN}$, como ocurre con más de la mitad de los casos de los internos entrevistados (CIDE, 2012: 98).

La impartición de Justicia es, según la Constitución Política de los Estados Unidos Mexicanos en su artículo 17, un bien gratuito al que todos tenemos el mismo derecho. Sin embargo, la realidad ha dejado ver que el acceso a la justicia, a pesar 
de ser universal y de que los servicios de las instituciones judiciales sean gratuitos, tiene distinta calidad partiendo del punto de que la mayoría de los ciudadanos necesitan alguien que los represente ante las Cortes, pues este representante puede ser gratuito si lo otorga el Estado y oneroso si se trata de un servicio privado. La Justicia es un bien que debe ser garantizado por el Estado, pero el gasto que debe solventarse no es solo el que destina el Estado al mantener al Poder Judicial con sus autoridades y sus procesos, un juicio conlleva otro tipo de gastos que serán hechos en otros rubros propios de la defensa.

Los abogados gratuitos o defensores de oficio que provee el Estado no tienen las condiciones laborales más competitivas, la sobrecarga de trabajo es una cuestión a considerar, pues los defensores de oficio llevan un promedio de 167 casos por año (Meza, 2015) mientras que un abogado penalista privado puede llevar un estimado de 40 a 90 casos por año, posiblemente con asistentes o un despacho jurídico. Mientras un abogado particular y su equipo se encargan de 3 a 8 casos por mes, un defensor de oficio debe repartir casi 14 casos en el mismo periodo de tiempo, lo equivalente a un caso cada dos días, eso si la distribución fuera uniforme y constante. Es difícil exigir a alguien en esta situación darles un seguimiento de la misma calidad a sus defendidos.

La actuación de los defensores de oficio, en contraste con la de los defensores privados, se muestra en la percepción de las encuestas a la población en reclusión (CIDE, 2009:42-46; y 2012: 84-145): En el caso del fuero común, para 2009 se registró que tres de cada cuatro internos habían contado con el defensor de oficio otorgado por el Estado, y solo uno de cada cuatro que están en prisión tuvo abogado privado. En estas mismas encuestas se respondió que únicamente el $27 \%$ de los defensores de oficio ofrecieron pruebas, en contraste al $67 \%$ de los defensores privados, no ofrecer pruebas para la defensa de un acusado, es equivalente a aceptar lo alegado en su contra; esto aunado al entorno de incertidumbre provocado por no entender el lenguaje jurídico, puede dejar sin esperanzas a cualquier acusado; de los defensores de oficio solamente $41 \%$ explicó a sus representados, contra $77 \%$ de los defensores privados; todo esto repercute en la sensación de ser defendido, relacionada con la satisfacción del derecho a un juicio justo y una defensa adecuada, uno de los derechos más vulnerados en el proceso judicial, pues la defensa de oficio brindada por el Estado solo fue capaz de hacer sentir protegido al acusado en $7 \%$ de las ocasiones.

Esos resultados permiten interpretar otro hallazgo: lo ideal para un ciudadano común es estar preparado económicamente para hacer frente al proceso judicial, a pesar de ser inocente, pues existe la posibilidad de que alguien le acuse injustamente, o que se le retenga en prisión preventiva mientras se demuestra su inocencia. De otro modo, si se deja guiar por el principio de gratuidad, y no invierte recursos propios en una apropiada defensa privada, debe estar consciente de que se trata de una defensa que probablemente sea de menor calidad con los defensores de oficio.

El pago por los servicios no es igual de competitivo al que puede llegar a recibir un defensor privado, esto no contribuye al prestigio y el estatus del defensor de oficio. Los salarios percibidos por los abogados particulares son más variados, en razón al número de asuntos postulados, y a la tarifa que ellos mismos estipulan con el cliente. El valor de la defensa suele ir en relación al monto de lo acusado, un porcentaje que no es forzoso y que puede establecer el abogado en el contrato de servicios; si pensamos en un promedio de precios entre $\$ 20$ y $\$ 25$ mil MXN para defender una acusación de robo de mediana cuantía, no todos los sectores de la población serían capaces de pagar por esta defensa privada. 
¿Quiénes tienen las posibilidades para pagar por una adecuada defensa privada? Para ello es necesario tener una parte del ingreso ahorrado o disponible específicamente para el momento en que haya que acudir ante la justicia, pero la distribución de ingresos no les permite a todos los ciudadanos la misma capacidad ahorrativa. En México cerca de la mitad de la población puede ser considerada pobre o vulnerable en algún sentido. De acuerdo con los datos de la Encuesta Nacional de Ingresos y Gastos de los Hogares (INEGI) en 2014, en México 11,4 millones de personas tenían un ingreso inferior a la línea de bienestar mínimo, lo cual significa que el $9,5 \%$ de los mexicanos se consideran en pobreza extrema, obteniendo en promedio un ingreso de $\$ 1.242 \mathrm{MXN}$ en un contexto urbano y de \$868 MXN en uno rural, lo cual no es suficiente ni para cubrir la necesidad alimentaria más fundamental. Además, 63,8 millones obtienen un ingreso que no permite la vida digna, que no pasa de $\$ 2.542 \mathrm{MXN}$ en la zona urbana y de $\$ 1.614$ MXN en una zona rural. Eso significa que, en total, el $46,2 \%$ de la población es pobre, moderadamente o en extremo, con alguna carencia o más, por debajo de la línea de bienestar mínimo.

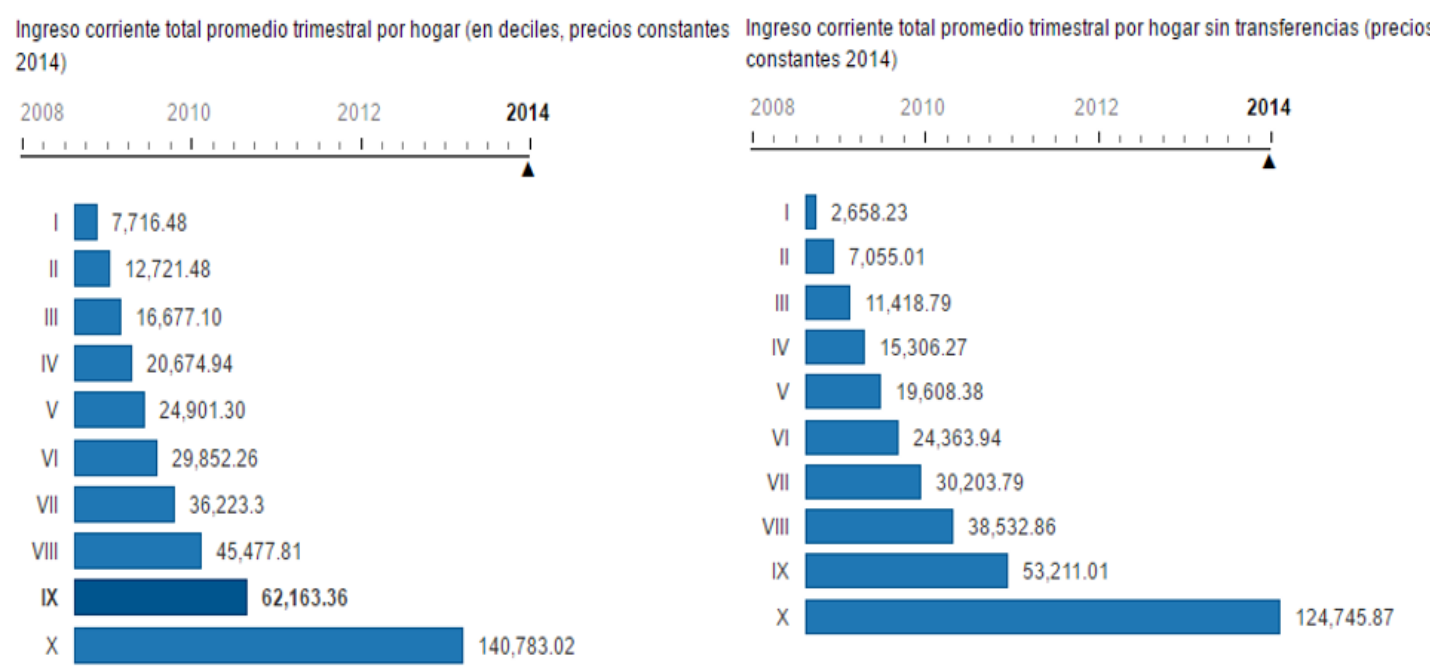

Gráfica 5 - Deciles de población por Ingreso con/sin transferencias.

Fuente: Encuesta Nacional de Ingresos y Gastos de los Hogares -ENIGH, INEGI, 2015

Suponiendo que es el mismo asunto del que son acusados el ciudadano promedio del primer y último decil de ingresos, y que el abogado, aún sin conocerlos, ha fijado la tarifa en $\$ 25.000$ MXN por llevar el mismo tipo de asunto, ¿Qué implicaría ese mismo gasto para una familia de 4 integrantes en cada decil económico? Tomando el salario integrado con las transferencias estatales (los apoyos gubernamentales de distinta índole), alguien en el decil inferior (Hogar A) obtiene en promedio $\$ 7.716 \mathrm{MXN}$ al mes ( $\$ 15.432 \mathrm{MXN}$ si los dos padres trabajan con el mismo ingreso), y en el decil superior (Hogar B) obtienen $\$ 140.783 \mathrm{MXN}$ al mes (\$281.566 MXN si fueran dos ingresos equivalentes del mismo decil). Usemos el caso más probable, en el que solo una persona en la casa sea quien recibe el ingreso. Lo necesario para una vida digna en el contexto urbano, para una vivienda de 4 personas es equivalente a $\$ 10.161 \mathrm{MXN}$, y solamente para comer se necesitan $\$ 4.968 \mathrm{MXN}$ por vivienda de 4 personas. El Hogar A no tiene un ingreso suficiente para satisfacer los elementos de una vida digna, aunque si gastase solamente lo necesario para comer, tendría disponibles $\$ 2.748 \mathrm{MXN}$ al mes, aunque ello implica una serie de carencias en otros muchos aspectos, este Hogar A tendría que ahorrar 
sin cumplir ninguna otra necesidad básica excepto comer durante 10 meses para poder pagar un defensor privado en este supuesto, o endeudarse por un monto que si agregamos intereses terminaría de pagar por lo menos en un año, eso si no gasta en algo más que la comida durante ese año. El Hogar B puede solventar todas las necesidades para una vida digna, y aun así los ingresos restantes serían de $\$ 130.622$ MXN con lo que puede pagar fácilmente el abogado privado, incluso al dividir el salario en 30 días, resulta que podría pagar este tipo de abogado con el ahorro correspondiente a 5 días de salario. Un hallazgo relativo a la desigualdad en el acceso a una defensa adecuada revela que, a pesar de que el ingreso sea entre 20 y 30 veces más alto, la diferencia entre los recursos disponibles luego de satisfacer las necesidades más básicas produce una desigualdad mayor, a fin de cuentas.

Además de la diferencia económica derivada del ingreso, hay otros beneficios que tiene la élite político-económica en cuanto a los vínculos con las instituciones estatales que aumentan sus atribuciones por medios informales, obteniendo facilidades mediante sobornos, compadrazgos, influencias o hasta inmunidad en ciertas posiciones.

La corrupción favorece a ciertas partes de la sociedad en perjuicio del resto, implica que las funciones institucionales sufren un desgaste, que el presupuesto asignado no sea suficiente, deteniendo el avance en cuestiones como la justicia, y toda una serie de necesidades básicas que se cubren con el mismo presupuesto desviado. La corrupción provoca un desgaste de las instituciones, promoviendo la separación social, es un mecanismo de refuerzo de la desigualdad, al igual que la impunidad.

Si todavía sigue existiendo corrupción, es porque ha dado resultado a quienes la llevan a cabo, ha sido mayor el beneficio obtenido en comparación al riesgo que corren. Así, la corrupción se convierte en una influencia socioeconómica sobre el actuar de la autoridad, inclusive en distintas partes del proceso de justicia. En las mismas Encuestas a la Población en Reclusión (CIDE, 2012: 84-145), los internos respondieron preguntas como: "de los abogados que tuvo ¿alguno le pidió dinero para dárselo a alguna autoridad?, ¿alguna de las autoridades le pidió dinero?, ¿cree usted que algún interno ha pagado para obtener beneficios preliberación?, ¿en algún momento creyó que podía evitar la cárcel si hubiera tenido influencias o dinero para pagar algún soborno? o, ¿si hubiera dado dinero a los policías que lo detuvieron, lo hubieran dejado ir?"

Cruzando la información de la media de dichas respuestas, y ponderando las posibilidades reales que tiene un delincuente en los deciles extremos de ingreso económico para sobornar, el de ingreso más alto contrastado con el de ingreso más bajo, se realizó una estimación en la gráfica de red entre los actores que interactúan en el proceso judicial, es por ello que se habían colocado previamente al victimario y su defensor en una posición central, pues en este caso, son ellos quienes pueden interesarse en sobornar a la autoridad para salirse con la suya. Cabe mencionar que en el actual proceso judicial acusatorio el rol de la víctima ha adquirido mayor protagonismo, pero no era así en el sistema que se analiza en este estudio.

La red se elaboró igualmente en Cytoscape, partiendo desde la Gráfica 2, pero quitando de ella los nodos de la cadena de justicia, dejando presentes solo a las autoridades, pues son las que son susceptibles de ser influenciadas. Para poder encontrar el siguiente hallazgo, en ella se expresan con una línea verde punteada las posibles interacciones entre los actores del proceso (cuyo valor fue de 1), y en 
una línea roja ondulada (con valor 2) se expresa una interacción en la que se puede dar la corrupción.

Comenzando por alguien del decil económico con menos ingresos, las posibilidades que tiene para sobornar se ven limitadas a pagar la defensa o el soborno, pues no cuenta con los ingresos suficientes ni para completar el pago completo de uno de ellos de manera inmediata. Probablemente el presunto agresor opte por pagar un soborno e intentar la salida fácil, ya sea a la víctima llegando a un arreglo antes de la detención, o bien al policía que lo detiene para obtener la libertad si es que se tiene el dinero necesario para sobornarles. Finalmente, otra opción es que se le asigne un defensor de oficio, y posteriormente sea este quien le solicite dinero para sobornar al Ministerio Público o al juez (no a los dos, pues los recursos son insuficientes). Son en total, tres oportunidades para obtener la libertad mediante la corrupción para alguien en el decil inferior de ingresos.

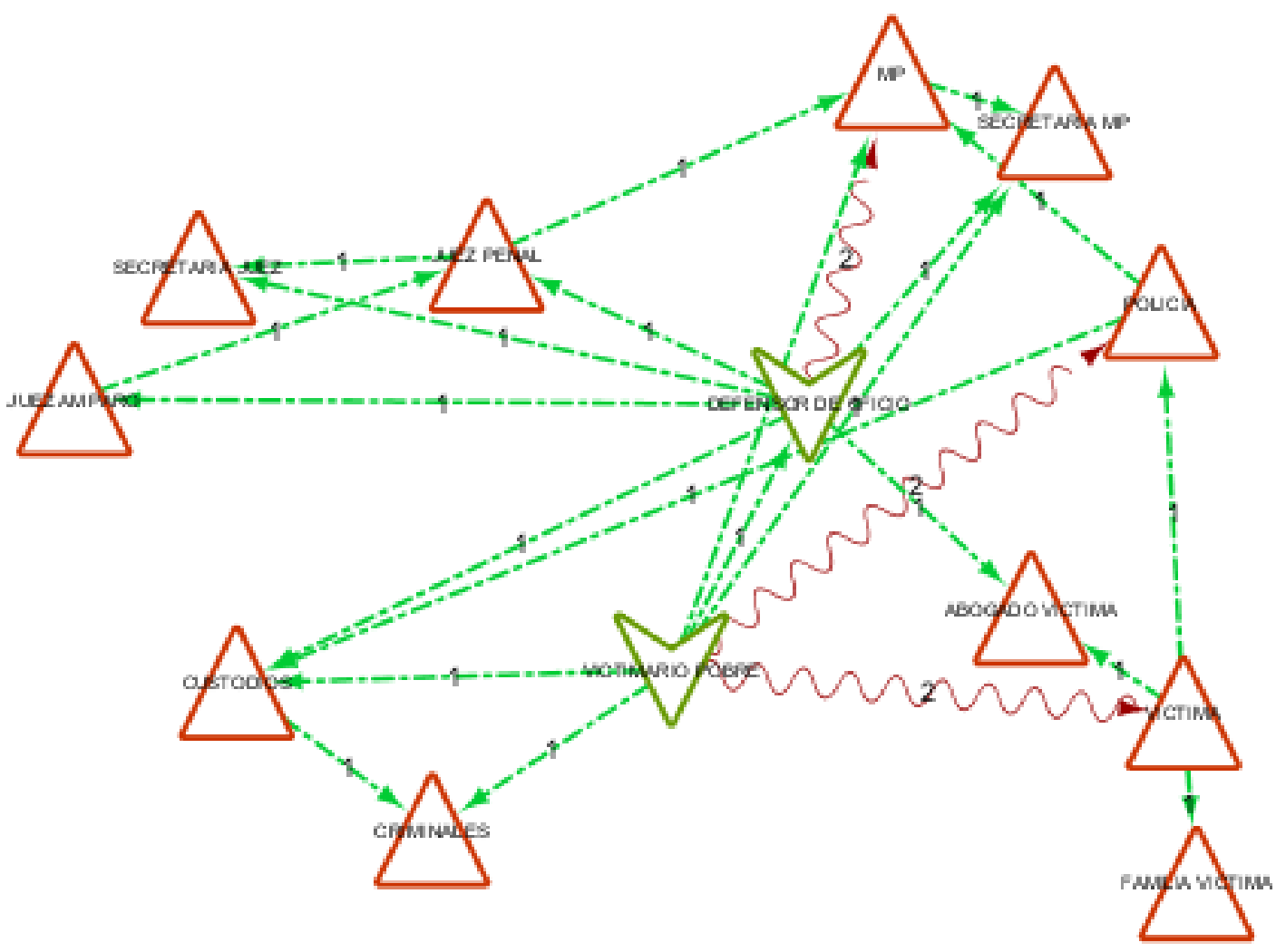

Gráfica 6 - Posibilidades de corrupción de un victimario con bajos ingresos y su defensor. Fuente: elaboración propia en Cytoscape

En contraste, alguien que pertenezca al decil con mayores ingresos, como es el caso de los miembros de la elite político-económica, tiene un panorama más holgado a su favor, con más del triple de oportunidades de sobornar a la autoridad por cuenta propia o mediante su defensor, esto aun sin incluir los vínculos políticos y los montos más elevados que puede ofrecer, siendo sobornos más atractivos y con mayores probabilidades de tener éxito en su objetivo. Por cuenta propia, el 
victimario con altos ingresos puede intentar sobornar a la víctima en el momento del crimen, al policía para evitar la detención, al Ministerio Público al momento de su presentación o incluso al Juez de Amparo para conseguir la suspensión de su proceso penal, dependiendo del tipo de agresión. Y mediante su defensor privado, el agresor podría sobornar a la víctima, al igual que a su familia y a su abogado, si es que los tiene, lo mismo con autoridades como el Juez penal, el Juez de segunda instancia y el agente del Ministerio Público. A pesar de que podría sobornar a otras autoridades como los custodios o los secretarios para obtener ciertos beneficios, esto no le otorgaría la libertad, por lo que no se les incluye en la Gráfica 7.

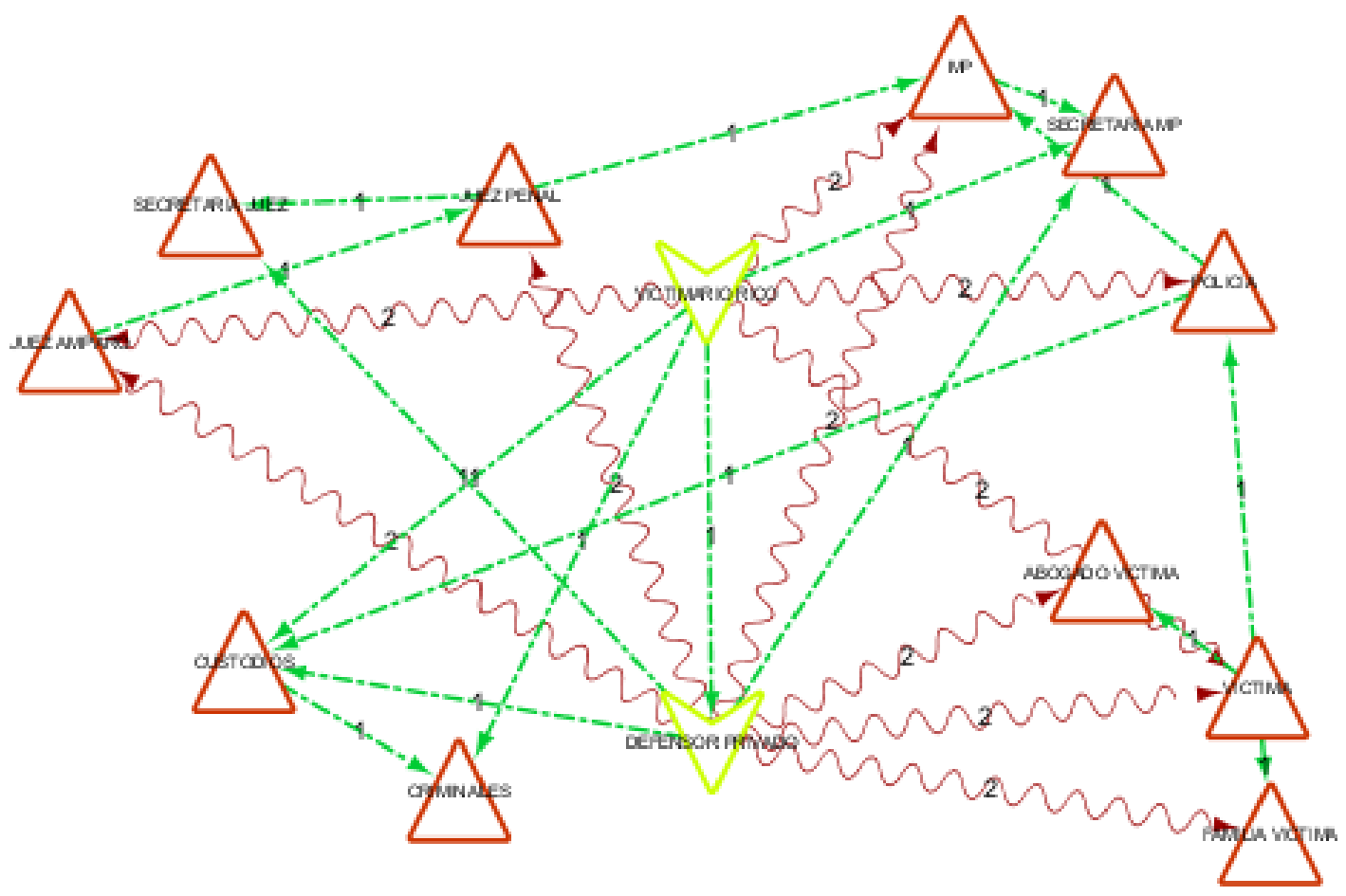

Gráfica 7 - Posibilidades de corrupción para un victimario de altos ingresos y su defensor. Fuente: elaboración propia en Cytoscape

Hay que recordar que el escenario descrito en las gráficas de red antes presentadas es simplemente un supuesto porque, de conseguir la libertad, el proceso ni siquiera se completaría y el resto de actores no aparecerían. La finalidad es mostrar el conjunto de probabilidades que podría tener un presunto criminal en distintos estratos económicos para sobornar e influenciar a la autoridad judicial.

\section{Conclusiones}

La interacción de la impunidad y la desigualdad socioeconómica de manera dinámica en una sociedad puede tener efectos indeseables que terminan por reforzar dichos problemas entre sí. La posición socioeconómica de los agresores tiene cierta injerencia en la impartición de Justicia, aunque no hay que dejar de lado otros factores importantes como la corrupción o las deficiencias del propio proceso judicial. Un aparato de Justicia disfuncional implica ciudadanos desprotegidos contra 
el crimen, y agresores que se pueden colocar por encima de la ley en repetidas ocasiones con la ayuda de recursos económicos o políticos.

Los principales hallazgos se han encontrado en las deficiencias de la administración de Justicia y en la posible corrupción que se da a lo largo de la cadena de justicia. Todo ello se ha observado a través de datos obtenidos en el sistema de Justicia penal mexicano inquisitivo, previo a la entrada en vigor del nuevo sistema acusatorio. La Justicia funciona de manera desigual a pesar de ir en contra de los presupuestos que le dan origen, las instituciones judiciales son sometidas a presiones, amenazas o sobornos que pueden mermar en su desempeño y aquellos que tienen más recursos también tienen mayores posibilidades de incidir en el funcionamiento de las instituciones o llegar a manipularlas a su favor.

La cadena de justicia en el sistema penal mexicano se ha identificado como débil en general, pero particularmente la policía como primer eslabón deja un gran vacío en las expectativas ciudadanas. Ha sido útil reflejar la cadena de justicia mediante gráficas de redes, destacando la importancia de los roles y las autoridades, pues con ello se han podido observar las partes más influenciables y los actores con mayor poder para esquivar la acción de la Justicia. El pobre desempeño de las autoridades de Justicia ha generado una falta de confianza en todas las instituciones de la cadena, lo que ocasiona posteriormente una renuencia general a denunciar los delitos y a tener una elevada cifra negra. Esto contribuye en gran medida a la impunidad general; aunque no hay que quitarle mérito a las deficientes actuaciones judiciales que también contribuyen a que la impunidad judicial vaya en aumento en cada etapa a lo largo del proceso de justicia penal.

Ha sido importante para los cálculos y datos obtenidos, la desigualdad en cuanto al ingreso, dado el carácter del pago de servicios de defensa que complementan el acceso a la justicia. Al final del proceso judicial, la desigualdad en el ingreso termina reflejándose como una desigualdad en el acceso a la justicia y en el derecho a una adecuada defensa. La desigualdad entre deciles de extremos opuestos para poder pagar una defensa privada, se determina mucho mayor a la desigualdad de ingreso original, afecta indirectamente en el resto de las capacidades y le da menor garantía a sus derechos de adecuada defensa al extremo con menores recursos, lo que para un extremo económico se puede pagar con unos cuantos días de salario, para otro extremo puede significar años de ingreso o de necesidades básicas sacrificadas, o incluso perderlo todo si no se está preparado para esas situaciones. Un rubro ilegal en donde también las oportunidades son desiguales, es la corrupción; de tal manera que son entonces comprensibles, más no justificables, los intentos por sobornar a las autoridades para seguir en libertad, en el entendido que para quien lo hace puede llegar a ser un gasto menor al pago de una adecuada defensa, o puede significar quedar libre de un tedioso proceso.

Los costes que van aparejados a la impartición de justicia dejan en posiciones favorables a quienes pueden defenderse con sus propios medios y en desventaja a quienes se atienen a la protección brindada por el Estado. Cuando la defensa que brinda el Estado no funciona como debería y la Justicia se administra parcialmente, dejando en la impunidad a más de 9 delitos de cada 10 que se cometen, es momento de cuestionar si las labores de protección que brinda el Gobierno son realmente en favor de la sociedad o solo de unos cuantos. Esto sin tomar en cuenta las agresiones impunes de iure que escapan a consideraciones legales que les harían merecedoras de castigo, dejando a ciertos actores blindados contra la justicia. 
Bibliografía

BAUMAN, Z. (2014), ¿La riqueza de unos pocos nos beneficia a todos?, Paidós, España

CIDE (2009), Resultados de la tercera encuesta a población en reclusión en el Distrito Federal y Estado de México. División de Estudios Jurídicos, CIDE, México, DF.

CIDE (2012), "Encuestas a la Población en Reclusión, Centro de Investigación y Docencia Económica A.C.", Red de Especialistas en seguridad Pública. Disponible en: http://seguridadpublica.cide.edu/bases-dedatos?p_p_id=148_INSTANCE_qv1lcY6UcE3D\&p_p_lifecycle $=0 \& p \_p \_s t a t e=n o$ rmal\&p_p_mode $=$ view\&p_p_col_id=column-

2\&p_p_col_count $=1 \& p \_r \_p \_564233524$ resetCur=true\&p_r_p_564233524_tag = encuestas+a+la+poblaci\%C3\%B3n+en+reclusi\%C3\%B3n (Fecha de consulta: 9 de mayo de 2017)

CONSULTA MITOFSKY (2012), México: Confianza en Instituciones; Tracking Poll Roy Campos, México D.F.

FOUCAULT, M. (1975), Vigilar y Castigar: Nacimiento de la Prisión, Siglo XXI, México.

GELLNER, E. (1991), Naciones y Nacionalismo, Alianza Editorial, México.

GOFFMAN, E. (2012), Estigma: La identidad deteriorada, Amorrortu, Buenos Aires.

ILLICH, I. (2011), Obras Reunidas, Volumen 1, Fondo de Cultura Económica, México.

INEGI, (2013a), "Censo Nacional de Procuración de Justicia, Instituto Nacional de Estadística y Geografía". Disponible en: http://www.inegi.org.mx/est/contenidos/proyectos/censosgobierno/cnpje2014/def ault.aspx (Fecha de consulta: 1 de mayo de 2017).

INEGI (2013b), "Encuesta Nacional de Victimización y Percepción Sobre Seguridad Pública",

Disponible

en:

http://www.beta.inegi.org.mx/proyectos/enchogares/regulares/envipe/2013/

(Fecha de consulta: 4 de abril de 2017).

INEGI, (2014), "Encuesta Nacional de Ingresos y Gastos de los Hogares - ENIGH".

Disponible

en: http://www.beta.inegi.org.mx/proyectos/enchogares/regulares/enigh/tradicional/2 014/ (Fecha de consulta: 2 de abril de 2017)

MARX, K. (1867), El Capital. Crítica de la Economía Política: Libro Primero - El Proceso de Producción del Capital, Siglo XXI, México.

MÉXICO EVALÚA, (2013), "La cárcel en México ¿Para qué?”, México Evalúa, México D.F.

MEZA, S. (2015), "Defensores públicos. Jugando en desventaja", CIDAC, México. Disponible en: http://proyectojusticia.org/odisea2016/defensores-publicos/ (Fecha de consulta: 1 de abril de 2017)

MUMFORD, L. (1997), Técnica y Civilización, Alianza, España

PIKETTY, T. (2014), Capital in the Twenty-First Century, Harvard Press, Estados Unidos.

POLANYI, K. (1944), La Gran Transformación. Los orígenes políticos y económicos de nuestro tiempo, Fondo de Cultura Económica, México.

RAPHAEL, R. (2014), Mirreynato: La Otra Desigualdad, Temas de Hoy, México.

SEN, A. (1992), Inequality Reexamined, Harvard University Press, Massachusetts.

SOUSA SANTOS, B. (2009) Sociología jurídica crítica: para un nuevo sentido común en el derecho, ILSA, Bogotá.

UDLAP (2015), "Índice Global de Impunidad, Centro de Estudios Sobre Impunidad y Justicia", Universidad de Las Américas, Puebla. Disponible en: http://udlap.mx/cesij/files/IGI_2015_digital.pdf (Fecha de consulta: 8 de mayo de 2017). 